\title{
A FAMÍlIA BIGNONIACEAE JUSS. (IPÊS) NO MUNICÍPIO DE LAVRAS, MINAS GERAIS
}

\author{
José Magno das Chagas Junior ${ }^{1}$, Douglas Antônio de Carvalho², Mariana Esteves Mansanares ${ }^{3}$
}

(recebido: 29 de setembro de 2009; aceito: 29 de julho de 2010)

\begin{abstract}
RESUMO: A família Bignoniaceae apresenta 120 gêneros e cerca de 800 espécies, com distribuição pantropical, ocorrendo principalmente nos neotrópicos. No Brasil, ocorrem 32 gêneros e cerca de 350 espécies, sendo esse país considerado o centro de diversificação da família. Em Minas Gerais, alguns levantamentos apontam a ocorrência de espécies como Dolichandra unguis-cati, Fridericia speciosa e Handroanthus chrysotrichus. Em Lavras, estudos apontam 58 espécies. O município localiza-se numa área de transição entre cerrado e florestas semideciduais, com relevo acidentado, o que promove uma grande diversidade de fisionomias vegetacionais. Objetivou-se catalogar as espécies de Bignoniaceae nativas e exóticas de Lavras, Minas Gerais, além da elaboração de uma chave de identificação para as mesmas. Foi realizado o levantamento de todas as exsicatas com registro de coleta no município, incorporadas no Herbário ESAL; também foram levantadas as espécies citadas em estudos fitossociológicos do município e registro de espécies ornamentais encontradas em praças, floriculturas e jardins da cidade. Os espécimes foram identificados in loco, por meio de comparações, consultas a especialistas e literatura taxonômica especializada. Encontraram-se 58 espécies (51 nativas e sete exóticas), distribuídas em 21 gêneros, dos quais Jacaranda (10 espécies), foi o mais representativo, seguido por Fridericia (8 espécies) e Handroanthus (7 espécies). Entre as espécies ornamentais destacaram-se Handroanthus impetiginosus (Ipê-roxo) e Handroanthus serratifolius (Ipê-amarelo). O número de espécies encontradas foi superior a de outras localidades, sendo a maior semelhança observada com espécies do Parque Estadual do Itacolomi, Minas Gerais.
\end{abstract}

Palavras-chave: Florística, taxonomia, sul de Minas Gerais.

\section{THE BIGNONIACEAE JUSS. FAMILY (IPES) IN THE MUNICIPAL DISTRICT OF LAVRAS, MINAS GERAIS}

\begin{abstract}
The Bignoniaceae family has 120 genera and 800 species with pantropical distribution, occurring mainly in the neotropics. About 32 genera and 350 species occur in Brazil, which is considered the center of diversity of the family. In Minas Gerais, some surveys indicate the occurrence of species such as Dolichandra unguis-cati, Fridericia speciosa and Handroanthus chrysotrichus. Lavras studies show 58 species. The municipality is located in a transition zone between savanna and semideciduous forest, with rugged terrain, which promotes a diversity of vegetation physiognomy. The objective was to catalog the species of native and exotic Bignoniaceae of Lavras, Minas Gerais, besides the elaboration of an identification key for them. Data were collected from all herbarium specimens with record collection in the city incorporated in the Herbarium ESAL; species cited in phytosociological studies of the county and registration of ornamental species found in parks, gardens and nurseries of the city were also raised. The specimens were identified in situ, by comparisons, consultations with specialists and specialized taxonomic literature. Fifty eight species (51 native and seven exotic) were found, distributed in 21 genera, of which Jacaranda (10 species) was the most common, followed by Fridericia (8 species) and Handroanthus ( 7 species). Among the ornamental species stood out Handroanthus impetiginosus (Purpleipe) and Handroanthus serratifolius (Yellow-ipe). The number of species was superior to other localities, the largest similarity observed was with species of Itacolomi State Park, Minas Gerais.
\end{abstract}

Key words: Floristic, taxonomy, southern Minas Gerais.

\section{INTRODUÇÃO}

A família Bignoniaceae Juss. é representada por cerca de 120 gêneros e 800 espécies arbóreas, arbustivas e trepadeiras, com distribuição pantropical e pronunciada ocorrência nos neotrópicos (SILVA \& QUEIROZ, 2003; SOUZA \& LORENZI, 2008). A família é subdividida em oito tribos, ocorrendo três delas no Brasil (Bignonieae,
Crescentieae e Tecomeae), as quais se diferenciam pelo hábito da planta e pela morfologia do fruto (BUREAU \& SCHUMANN, 1897; GENTRY, 1980). O Brasil apresenta alguns táxons endêmicos e é considerado o centro de diversidade da família, com 32 gêneros e 350 espécies ocorrendo em vários tipos de ambiente, desde o cerrado até florestas úmidas perenifólias (GENTRY, 1980; SILVA \& QUEIROZ, 2003; SOUZA \& LORENZI, 2008).

\footnotetext{
${ }^{1}$ Graduando em Ciências Biológicas, Bolsista PIBIC/CNPq - Universidade Federal de Lavras/UFLA - Cx. P. 3037 - $37200-000$ - Lavras, MG - jmagnobio@gmail.com

${ }^{2}$ Agrônomo, Professor Dr. em Biologia Vegetal - Departamento de Biologia - Universidade Federal de Lavras/UFLA - Cx. P. 3037 37200-000 - Lavras, MG - douglasc@dcf.ufla.br

${ }^{3}$ Bacharel em Ciências Biológicas, Professora Ph.D. em Botânica - Departamento de Biologia - Universidade Federal de Lavras/UFLA Cx. P. 3037 - 37200-000 - Lavras, MG - m.mansanares@ gmail.com
} 
De acordo com Lorenzi (2008), a exuberância durante o florescimento faz com que muitas espécies de Bignoniaceae sejam utilizadas na arborização de ruas, praças, parques e avenidas. A madeira dos exemplares dessa família é amplamente utilizada como matéria-prima de diversos artigos da carpintaria e marcenaria, sendo também de grande utilidade na construção civil e naval (LORENZI, 2008). Nos últimos anos tem-se verificado cada vez mais o uso de espécies da família na medicina, como nos estudos de Agra et al. (2007, 2008) e Hiruma-Lima \& Di Stasi (2002) os quais detectaram que o macerado das folhas de Jacaranda caroba DC. em aguardente pode ser aplicado externamente como cicatrizante e contra úlceras. Já se observou, também, atividade bactericida (PARK et al., 2005), fungicida (PORTILLO et al., 2001), antiofídica (NUÑEZ et al., 2004) e antitumoral (CHENNA et al., 2001) de substâncias presentes no cerne e na casca de espécies do gênero Tabebuia (Handroanthus).

Dando sequência aos estudos das famílias de plantas no município de Lavras e complementando os estudos sobre a família Bignoniaceae no Brasil, objetivou-se catalogar as espécies nativas e exóticas dessa família no município e a elaboração de uma chave de identificação para elas.

\section{MATERIAL E MÉTODOS}

\section{1 Área de Estudo}

O município de Lavras localiza-se na região do Alto Rio Grande, inserido na mesorregião dos Campos das Vertentes, Sul de Minas Gerais, com cotas altitudinais na faixa dos 500-1200 metros e aproximadamente 564,5 $\mathrm{Km}^{2}$ (INSTITUTO BRASILEIRO DE GEOGRAFIA E ESTATÍSTICA - IBGE, 2009; QUEIROZ et al., 1980). O clima é do tipo tropical de altitude caracterizado por invernos secos e verões amenos, com temperatura média anual de $19,4^{\circ} \mathrm{C}$ e pluviosidade média anual de $1529,5 \mathrm{~mm}$, concentrada nos meses de novembro a fevereiro (DEPARTAMENTO NACIONAL DE METEOROLOGIA - DNMet, 1992). A região é caracterizada por topografia acidentada e montanhosa, o que promove uma grande variação ambiental. A flora local é bastante diversificada, com existência de vários tipos de vegetação, com áreas de transição entre os cerrados do Brasil Central e florestas semideciduais do Sudeste e Sul do País. De uma maneira geral, as fisionomias de campo rupestre e campo de altitude estão associadas aos solos rasos e jovens do alto das montanhas, enquanto nas altitudes menores, predominam solos mais antigos e profundos, ocorrendo áreas de cerrados ou florestas, discriminados pela fertilidade do solo, regime de água e frequência de incêndios (OLIVEIRA-FILHO et al., 1994a).

\subsection{Levantamento das espécies}

Foi realizado em três etapas, no período de agosto/ 2008 a fevereiro/2009. A primeira etapa consistiu em registrar todas as exsicatas da família ocorrentes no município, presentes no Herbário ESAL, do Departamento de Biologia da Universidade Federal de Lavras (UFLA). Na segunda, listaram-se as espécies citadas em publicações sobre a flora do município: florística geral (CARVALHO, 1992; GAVILANES \& BRANDÃO, 1991a,b; GAVILANES et al., 1992), mata do Poço Bonito (DALANESI et al., 2004; OLIVEIRA-FILHO et al., 1994a,b), Reserva Florestal UFLA (OLIVEIRA-FILHO et al., 1994b), mata do Capivari (SOUZA et al., 2003), mata da Subestação (ESPÍRITO SANTO et al., 2002), mata da Lagoa (MACHADO et al., 2004), Parque Florestal do Rio Bonito (OLIVEIRA-FILHO \& FLUMINHAN-FILHO, 1999), etnobotânica de Cerrados e Florestas Semideciduais (RODRIGUES \& CARVALHO, 2007, 2008), corredores ecológicos (APPOLINÁRIO, 2008) e bacia hidrográfica do ribeirão Santa Cruz (PINTO et al., 2005), e por último, fez-se o levantamento das espécies ornamentais encontradas nas praças, floriculturas e jardins residenciais da cidade. As espécies ornamentais foram fotografadas e identificadas in loco, por meio de comparação em herbário ou ainda com o auxílio de especialistas e literatura taxonômica especializada. A partir das espécies levantadas, foi elaborada uma chave analítica dicotômica, utilizando-se características morfológicas vegetativas e/ou reprodutivas.

\section{RESULTADOS E DISCUSSÃO}

A família está representada no município por 58 espécies (51 nativas e 7 exóticas), distribuídas em 21 gêneros (Tabela 1). Jacaranda foi o gênero mais representativo com dez espécies, seguido por Fridericia (oito), Handroanthus (sete), Anemopaegma e Cuspidaria (quatro), Tabebuia $e$ Tanaecium (três), Adenocalymma, Amphilophium, Bignonia, Dolichandra e Zeyheria (duas) e Cybistax, Lundia, Podranea, Pyrostegia, Spathodea, Stizophyllum, Tecoma, Tynanthus e Xylophragma com apenas uma espécie cada. Essas espécies foram registradas em diferentes tipos de formações vegetais: floresta estacional semidecidual e cerrado, incluindo áreas de campo rupestre e campo limpo. Segundo Gentry (1980), as Bignoniaceae podem ser encontradas desde os cerrados abertos até as florestas úmidas e perenifólias. As trepadeiras formam o grupo mais diverso, com cerca de 30 espécies, representando $52 \%$ do total, enquanto as arbóreas e arbustivas apresentam 20 e 8 espécies, respectivamente. Algumas espécies se destacaram no município. Pyrostegia venusta, uma espécie trepadeira que

Cerne, Lavras, v. 16, n. 4, p. 517-529, out./dez. 2010 
apresenta ampla ocorrência no município de Lavras, com registros em formações florestais, no cerrado e em áreas alteradas pela ação antrópica, como terrenos baldios e margens de rodovias. Essa espécie apresenta uma ampla distribuição geográfica, podendo ser encontrada em todo o Brasil, em regiões do Paraguai, Bolívia e nordeste da Argentina e é considerada a única espécie invasora da família, pelo fato de se estabelecer em meio a culturas e pastagens (GOBATTORODRIGUES \& STORT, 1992; SANDWITH \& HUNT, 1974). Jacaranda caroba, com porte variando de arbusto a arvoreta, ocorre em Lavras, nas áreas de cerrado, campo rupestre e campo limpo, o que se apoia no padrão de distribuição demonstrado por Gentry (1992), o qual a considera como uma espécie exclusiva do cerrado. No entanto, Pereira \& Mansano (2008) ampliaram o padrão de distribuição dessa espécie com registros para outros tipos vegetacionais. Lohmann \& Pirani (1996) relatam a presença dessa espécie desde o estado da Bahia até o Paraná. Em estudos fitossociológicos realizados no município de Lavras, Handroanthus ochraceus é a espécie mais frequente, ocorrendo em várias áreas de formações florestais: na mata ciliar do córrego dos Vilas Boas (OLIVEIRAFILHO et al., 1994); em uma floresta semidecídua às margens do Rio Capivari (SOUZA et al., 2003); na floresta do Parque Ecológico Quedas do Rio Bonito (DALANESI et al., 2004). Apesar de ser uma espécie de ipê-amarelo muito comum no município, é pouco utilizada em projetos paisagísticos. Gentry (1992), caracterizou-a como elemento típico do cerrado brasileiro, mas podendo ocorrer também em florestas, o que de fato pode ser observado no presente trabalho. Fridericia platyphylla, que ocorre nos cerrados de Lavras, é encontrada também em áreas de caatinga e campos gerais na região de Catolés, na Bahia (SILVA \& QUEIROZ, 2003), em áreas de campo rupestre e floresta estacional no Parque Estadual do Itacolomi, em Minas Gerais (ARAÚJO, 2008), e nos Parque Estadual do Rio Doce e Parque Nacional da Serra da Canastra (SCUDELLER, 2004; SCUDELLER \& CARVALHO-OKANO, 1998). Scudeller (1997) considera tal espécie comum em diversos tipos de formações vegetais, sendo encontrada nos estados do Acre, Maranhão, Mato Grosso, Goiás, Bahia, Minas Gerais, Espírito Santo, Rio de Janeiro e São Paulo. Jacaranda subalpina, uma espécie arbórea que ocorre em Lavras em formações florestais (DALANESI et al., 2004). Pereira \& Mansano (2008) foram os únicos que também catalogaram esse táxon em seu levantamento, realizado no Parque Nacional do Itatiaia. Segundo Gentry (1992), referida espécie encontra-se restrita à Floresta Pluvial Montana na Serra da Mantiqueira, nos estados do RJ, MG e SP e na Serra do Caraça, em Minas Gerais. É o único exemplar da família, presente em Lavras, que se encontra listado como vulnerável, segundo o Biodiversitas (2009).

No levantamento realizado em praças, floriculturas e jardins residenciais da cidade encontraram-se 13 espécies, sendo Handroanthus impetiginosus e $H$. serratifolius as mais utilizadas. A primeira é um ipê-roxo, que segundo Lorenzi (2008) ocorre do Piauí e Ceará até Minas Gerais, Goiás e São Paulo, na mata pluvial atlântica, em florestas semidecíduas e ocasionalmente no cerrado. Aquele autor ainda menciona que é a espécie de ipê-roxo mais utilizada no paisagismo das cidades do sudeste e centro-oeste brasileiro. Já $H$. serratifolius é a espécie de ipê-amarelo mais utilizada no paisagismo de Lavras. Conhecida como a "árvore símbolo do Brasil", esse táxon ocorre com frequência na região amazônica, estendendose de maneira mais esparsa do Ceará até São Paulo (LORENZI, 2008).

O município de Lavras, conhecido como "Terra dos Ipês e das Escolas", pelo fato de apresentar na sua flora nativa e exótica várias espécies de ipês e de ser um centro de importantes e tradicionais instituições de ensino, possui 11 espécies de ipês: seis de flores amarelas (Handroanthus albus, $H$. chrysotrichus, $H$. ochraceus, $H$. serratifolius, $H$. vellosoi e Tabebuia aurea), uma de flor branca (Tabebuia roseoalba), três de flores roxas (Handroanthus heptaphyllus, H. impetiginosus e Tabebuia heterophylla) e uma de flor verde (Cybistax antisyphilitica).

Compararam-se os resultados obtidos no presente trabalho com cinco levantamentos realizados no Brasil, em áreas de campo rupestre, floresta estacional semidecidual, cerrado, caatinga e carrasco, localizados em áreas de preservação ambiental, nos estados do Rio de Janeiro e Minas Gerais e em uma região da Chapada Diamantina, no estado da Bahia (Tabela 2). Todas as áreas apresentaram uma menor riqueza de Bignoniaceae em relação ao município de Lavras. O Parque Estadual do Itacolomi foi o que apresentou o maior número de espécies em comum com o município de Lavras. No entanto, deve-se considerar que um dos artigos analisou somente a tribo Bignonieae (SCUDELLER \& CARVALHOOKANO, 1998) e outro somente a tribo Tecomeae (PEREIRA \& MANSANO, 2008). Ainda, em levantamento realizado por Carvalho \& Martins (2009) nos cerrados do sudoeste de Minas Gerais, observou-se que das oito espécies de Bignoniaceae arbóreo-arbustivas registradas, sete encontram-se em Lavras, não ocorrendo nesse município somente a espécie arbustiva Memora peregrina (Miers) Sandwith.

Diante dos resultados obtidos no presente estudo, verificou-se que a família Bignoniaceae contribui de forma expressiva na riqueza de espécies de angiospermas na flora do município de Lavras, MG, tanto no que se refere à flora nativa quanto às espécies usadas no paisagismo da cidade.

Cerne, Lavras, v. 16, n. 4, p. 517-529, out./dez. 2010 
Chave analítica dicotômica para os Gêneros e Espécies de Bignoniaceae presentes no município de Lavras, Minas Gerais:

1- Plantas sem gavinhas ..............................................................................................2

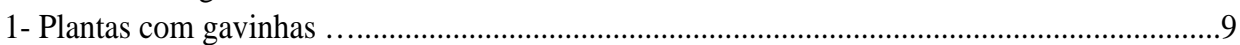

2- Hábito trepador ........................................................................Podranea (P. ricasoliana)

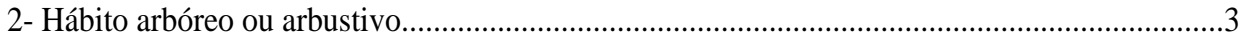

3- Inflorescência em panícula.............................................................Handroanthus (Chave H)

3- Inflorescência em racemo ou tirso................................................................................

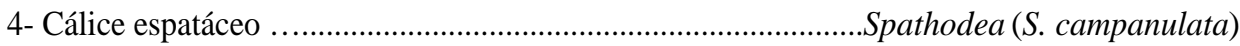

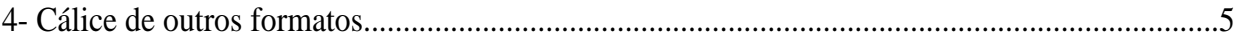

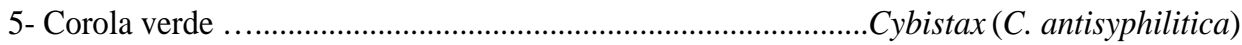

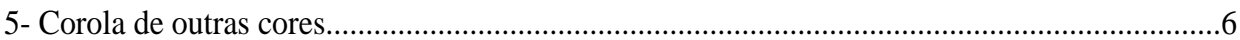

6- Folhas pinadas ou bipinadas.............................................................................................

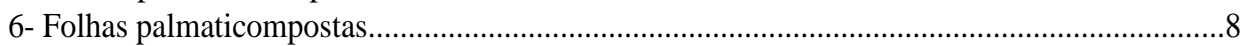

7- Inflorescência em tirso........................................................................Jacaranda (Chave I)

7- Inflorescência em racemo..........................................................................Tecoma (T. stans)

8- Flor acastanhada; fruto circular a obovoide............................................eyheria (Chave L)

8- Flor branca, amarela ou lilás; fruto linear alongado a oblongo............Tabebuia (Chave J)

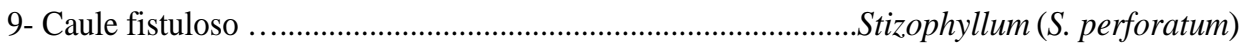

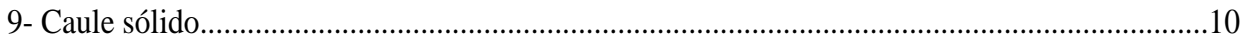

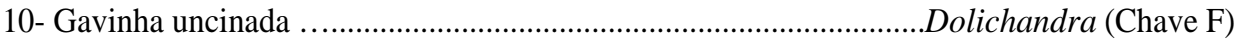

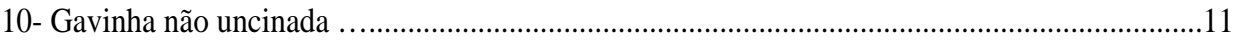

11- Presença de disco adesivo na gavinha ...................................Amphilophium (Chave B)

11- Ausência de disco adesivo na gavinha ........................................................................12

12- Caule hexagonal ............................................................................Pyrostegia (P. venusta)

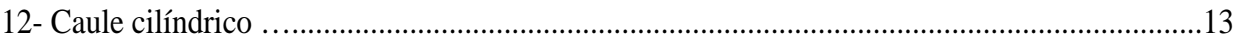

13- Antera densamente pubescente...............................................................undia (L. obliqua)

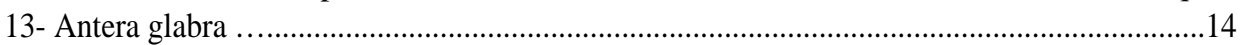

14- Pecíolo articulado no caule .......................................................Adenocalymma (Chave A)

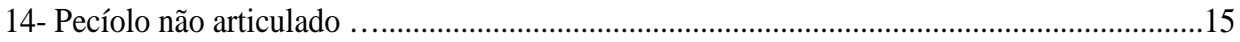

15- Cálice cupular .................................................................................Tanaecium (Chave K)

15- Cálice truncado ou 5-partido .......................................................................................16

Cerne, Lavras, v. 16, n. 4, p. 517-529, out./dez. 2010 
16- Disco nectarífero pobremente desenvolvido

.Tynanthus (T. elegans)

16- Disco nectarífero anular

17- Inflorescência em racemo

Anemopaegma (Chave C)

17- Inflorescência em tirso

18- Cálice coriáceo; sementes com asas opacas

Bignonia (Chave D)

18- Cálice membranoso, sementes com asas hialinas

19- Corola glabra; óvulos em 2 séries em cada placenta

Cuspidaria (Chave E)

19- Corola pubescente; óvulos em 1 série ou séries múltiplas

20- Séries múltiplas de óvulos em cada placenta

Fridericia (Chave G)

20- Séries simples de óvulos em cada placenta Xylophragma (X. platyphyllum)

\section{Chave A, para as espécies do gênero Adenocalymma:}

1- Pseudoestípula com glândula pateliforme; corola tubular.....Adenocalymma bracteatum

1- Pseudoestípula inconspícua; corola infundibuliforme. Adenocalymma sp.

\section{Chave B, para as espécies do gênero Amphilophium:}

1- Presença de pseudoestípula; cálice costado. Amphilophium crucigerum

1- Ausência de pseudoestípula; cálice tubuloso .Amphilophium elongatum

\section{Chave C, para as espécies do gênero Anemopaegma:}

1- Fruto cápsula ovoide Anemopaegma arvense

1- Fruto cápsula elíptica

2- Corola campanulada Anemopaegma glaucum

2- Corola tubular .3

3- Gavinha trífida Anemopaegma chamberlaynii

3- Gavinha simples. Anemopaegma sp.

\section{Chave D, para as espécies do gênero Bignonia:}

1- Gavinha simples; inflorescência terminal. Bignonia magnifica

1- Gavinha multífida; inflorescência axilar. ..Bignonia sp.

\section{Chave E, para as espécies do gênero Cuspidaria:}

1- Pseudoestípula cônica Cuspidaria convoluta

1- Pseudoestípula inconspícua ou ausente. ....2

2- Corola campanulada. Cuspidaria multiflora

2- Corola tubular. .3

3- Flores purpúreas ..Cuspidaria pulchra

3- Flores beges a cremes .Cuspidaria sp.

Cerne, Lavras, v. 16, n. 4, p. 517-529, out./dez. 2010 
Chave F, para as espécies do gênero Dolichandra:

1- Cálice campanulado

Dolichandra unguis-cati

1- Cálice espatáceo Dolichandra sp.

\section{Chave G, para as espécies do gênero Fridericia:}

1- Hábito arbustivo Fridericia platyphylla

1- Hábito trepador... . .2

2- Corola infundibuliforme Fridericia samydoides

2- Corola campanulada ou tubulosa. .3

3- Corola tubulosa.

3- Corola campanulada

4- Ramo lepidoto

Fridericia speciosa

4- Ramo glabro. Fridericia $s p$.

5- Ramo glabro a lepidoto. Fridericia florida

5- Ramo tomentoso ...6

6- Inflorescência em panícula Fridericia formosa

6- Inflorescência em tirso.

7- Disco nectarífero cupular Fridericia pubescens

7- Disco nectarífero pateliforme Fridericia triplinervia

\section{Chave H, para as espécies do gênero Handroanthus:}

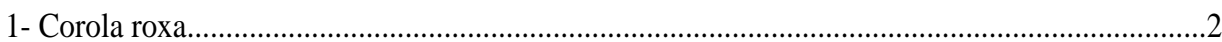

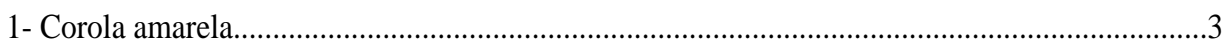

2- Folíolo membranáceo....................................................................................... heptaphyllus

2- Folíolo coriáceo............................................................................................. impetiginosus

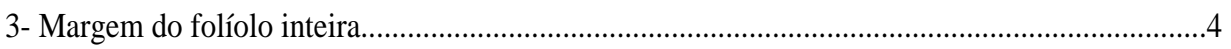

3- Margem do folíolo serreada a ondulada...............................................................................

4- Face adaxial pilosa; cálice tubular; flores sésseis.......................................... chrysotrichus

4- Face adaxial glabra; cálice infundibuliforme; flores com pedicelos...................... ochraceus

5- Cálice verde..................................................................................................H. serratifolius

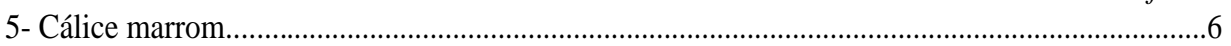

6- Ramos com tricomas estrelados; face adaxial do folíolo glabra, abaxial denso tomentosa; margem ondulada........................................................................................................... albus 6- Ramos glabros; face adaxial com tricomas esparso-estrelados, abaxial com tricomas denso-estrelados; margem conspicuamente serreada................................................ . vellosoi

Cerne, Lavras, v. 16, n. 4, p. 517-529, out./dez. 2010 
Chave I, para as espécies do gênero Jacaranda:

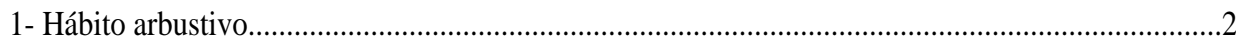

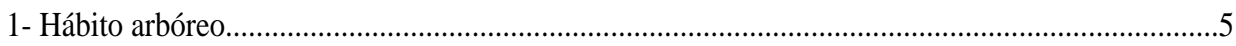

2- Folhas pinadas..................................................................................Jacaranda paucifoliata

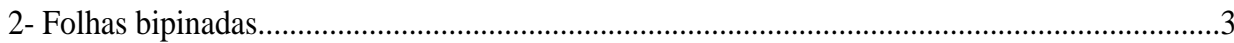

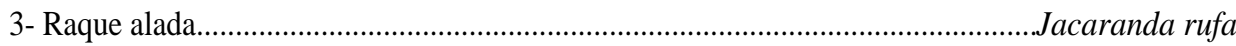

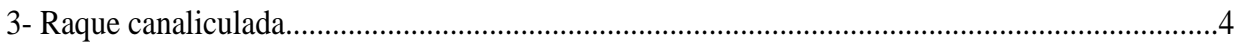

4- Folíolo decurrente.................................................................................Jacaranda decurrens

4- Folíolo completamente separado da raque....................................................Jacaranda caroba

5- Cálice cupular..................................................................................................................

5- Cálice campanulado, tubular-campanulado ou 5-dentado..........................................................

6- Ramo subtetragonal.............................................................................. Jacaranda macrantha

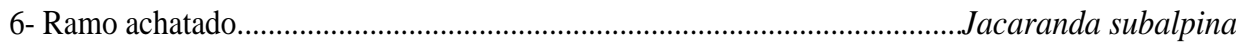

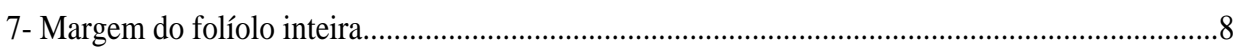

7- Margem do folíolo revoluta.................................................................................................... 9

8- Folíolo lanceolado.................................................................................Jacaranda cuspidifolia

8- Folíolo elíptico a oblongo-elíptico..........................................................Jacaranda micrantha

9- Folíolo oblongo a oblongo-lanceolado; margem do fruto plana.......................... acutifolia

9- Folíolo elíptico a linear-elíptico; margem do fruto sinuosa.................................... J. mimosifolia

Chave J, para as espécies do gênero Tabebuia:

1- Corola amarela

Tabebuia aurea

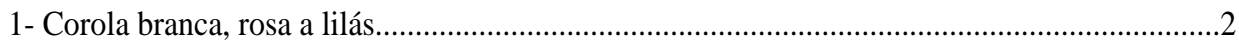

2- Folha com 5 folíolos; margem inteira a serrilhada..............................Tabebuia heterophylla

2- Folha com 3 folíolos; margem ondulada....................................................Tabebuia roseoalba

Chave K, para as espécies do gênero Tanaecium:

1- Folíolo oblongo-lanceolado.

Tanaecium neobrasiliense

1- Folíolo elíptico a ovado-elíptico.

2- Cálice cupular.

Tanaecium affine

2- Cálice campanulado. .Tanaecium selloi

\section{Chave L, para as espécies do gênero Zeyheria:}

1- Folíolos oblongos a ovais oblongos, margem revoluta; corola cilíndrica............ montana

1- Folíolos obovados, margem não revoluta; corola campanulada .................... tuberculosa 
Tabela 1 - Lista de espécies de Bignoniaceae ocorrentes no município de Lavras - Minas Gerais, com seus nomes populares, hábitos de crescimento e local de registro da espécie ( $\mathrm{F}=$ Floresta $\mathrm{C}=$ cerrado $\mathrm{O}=$ ornamentais $)$.

Table 1 - List of species of Bignoniaceae occuring in Lavras - Minas Gerais, with their popular names, growth habits and place of record of the species ( $F=$ forest $C=$ savana $O=$ ornamental).

\begin{tabular}{|c|c|c|c|c|c|}
\hline \multirow{2}{*}{ Espécies } & \multirow{2}{*}{ Nomes Populares } & \multirow{2}{*}{ Hábitos } & \multicolumn{3}{|c|}{ Local de registro } \\
\hline & & & $\mathrm{F}$ & $\mathrm{C}$ & $\mathrm{O}$ \\
\hline Adenocalymma bracteatum (Cham.) DC. & Cipó-branco & Trepadeira & $\mathrm{X}$ & & \\
\hline Adenocalymma sp. & - & Trepadeira & $\mathrm{X}$ & & \\
\hline Amphilophium crucigerum (L.) L.G.Lohmann & Pente-de-macaco & Trepadeira & $\mathrm{X}$ & & \\
\hline Amphilophium elongatum (Vahl) L.G.Lohmann & - & Trepadeira & $\mathrm{X}$ & & \\
\hline Anemopaegma arvense (Vell.) Stellfeld ex de Souza & Catuaba & Arbusto & & $\mathrm{X}$ & \\
\hline Anemopaegma chamberlaynii (Sims) Bureau \& K. Schum. & Catuaba & Trepadeira & $\mathrm{X}$ & & \\
\hline Anemopaegma glaucum Mart. ex DC. & Catuaba & Arbusto & & $\mathrm{X}$ & \\
\hline Anemopaegma sp. & Catuaba & Trepadeira & $\mathrm{X}$ & & \\
\hline Bignonia magnifica $\mathrm{W}$. Bull & Sariteia & Trepadeira & & & $\mathrm{X}$ \\
\hline Bignonia sp. & - & Trepadeira & $\mathrm{X}$ & & \\
\hline Cuspidaria convoluta (Vell.) A.H.Gentry & Cipó-cruz & Trepadeira & $\mathrm{X}$ & & \\
\hline Cuspidaria multiflora DC. & - & Trepadeira & $\mathrm{X}$ & & \\
\hline Cuspidaria pulchra (Cham.) L.G.Lohmann & - & Trepadeira & & $\mathrm{X}$ & \\
\hline Cuspidaria sp. & - & Trepadeira & $\mathrm{X}$ & & \\
\hline Cybistax antisyphillitica (Mart.) Martius & Ipê-verde & Árvore & $\mathrm{X}$ & $\mathrm{X}$ & \\
\hline Dolichandra unguis-cati (L.) L.G.Lohmann & Unha-de-gato & Trepadeira & $\mathrm{X}$ & $\mathrm{X}$ & \\
\hline Dolichandra sp. & - & Trepadeira & & $\mathrm{X}$ & \\
\hline Fridericia florida (DC.) L.G.Lohmann & - & Trepadeira & & $\mathrm{X}$ & \\
\hline Fridericia formosa (Bureau) L.G.Lohmann & - & Trepadeira & & $\mathrm{X}$ & \\
\hline Fridericia platyphylla (Cham.) L.G.Lohmann & Cipó-una & Arbusto & & $\mathrm{X}$ & \\
\hline Fridericia pubescens (L.) L.G.Lohmann & - & Trepadeira & $\mathrm{X}$ & & \\
\hline Fridericia samydoides (Cham.) L.G.Lohmann & - & Trepadeira & $\mathrm{X}$ & & \\
\hline Fridericia speciosa Mart. & Cipó-quebrador & Trepadeira & & $\mathrm{X}$ & \\
\hline Fridericia triplinervia (Mart. ex DC.) L.G.Lohmann & - & Trepadeira & $\mathrm{X}$ & $\mathrm{X}$ & \\
\hline Fridericia sp. & - & Trepadeira & $\mathrm{X}$ & & \\
\hline Handroanthus albus (Cham.) Mattos & Ipê-amarelo-da-serra & Árvore & $\mathrm{X}$ & & \\
\hline Handroanthus chrysotrichus (Mart. ex DC.) Mattos & Ipê-tabaco & Árvore & $\mathrm{X}$ & & $\mathrm{X}$ \\
\hline Handroanthus heptaphyllus (Vell.) Mattos & Ipê-rosa & Árvore & & & $\mathrm{X}$ \\
\hline Handroanthus impetiginosus (Mart. ex DC.) Mattos & Ipê-roxo & Árvore & & $\mathrm{X}$ & $\mathrm{X}$ \\
\hline Handroanthus ochraceus (Cham.) Mattos & Piúva & Árvore & $\mathrm{X}$ & $\mathrm{X}$ & $\mathrm{X}$ \\
\hline
\end{tabular}

Cerne, Lavras, v. 16, n. 4, p. 517-529, out./dez. 2010 
Tabela 1 - Continua...

Table 1 - Continued...

\begin{tabular}{|c|c|c|c|c|c|}
\hline \multirow{2}{*}{ Espécies } & \multirow{2}{*}{ Nomes Populares } & \multirow{2}{*}{ Hábitos } & \multicolumn{3}{|c|}{ Local de registro } \\
\hline & & & $\mathrm{F}$ & $\mathrm{C}$ & $\mathrm{O}$ \\
\hline Handroanthus serratifolius (Vahl) S.O.Grose & Ipê-amarelo & Árvore & $\mathrm{X}$ & & $\mathrm{X}$ \\
\hline Handroanthus vellosoi (Toledo) Mattos & Ipê-amarelo & Árvore & $\mathrm{X}$ & & $\mathrm{X}$ \\
\hline Jacaranda acutifolia Bonpl.* & Jacarandá-caroba & Árvore & $\mathrm{X}$ & $\mathrm{X}$ & \\
\hline Jacaranda caroba (Vell.) DC. & Carobinha & Árvore & & $\mathrm{X}$ & \\
\hline Jacaranda cuspidifolia Mart. & Jacarandá-de-Minas & Árvore & $\mathrm{X}$ & $\mathrm{X}$ & \\
\hline Jacaranda decurrens Cham. & Carobinha & Arbusto & & $\mathrm{X}$ & \\
\hline Jacaranda macrantha Cham. & Carobão & Árvore & $\mathrm{X}$ & & \\
\hline Jacaranda micrantha Cham. & Carobão & Árvore & $\mathrm{X}$ & & \\
\hline Jacaranda mimosifolia D. Don* & Jacarandá-mimoso & Árvore & $\mathrm{X}$ & & $\mathrm{X}$ \\
\hline Jacaranda paucifoliata Mart. ex DC. & Jacarandá-da-terra & Arbusto & & $\mathrm{X}$ & \\
\hline Jacaranda rufa Silva Manso & Perobinha & Arbusto & & $\mathrm{X}$ & \\
\hline Jacaranda subalpina Morawetz & Caroba-do-campo & Árvore & $\mathrm{X}$ & & \\
\hline Lundia obliqua Sond. & - & Trepadeira & $\mathrm{X}$ & & \\
\hline Podranea ricasoliana (Tanfani) Sprague* & Sete-léguas & Trepadeira & & $\mathrm{X}$ & $X$ \\
\hline Pyrostegia venusta (Ker Gawl.) Miers & Cipó-de-São-João & Trepadeira & $\mathrm{X}$ & $\mathrm{X}$ & \\
\hline Spathodea campanulata P. Beauv.* & Tulipeira & Árvore & & & $\mathrm{X}$ \\
\hline Stizophyllum perforatum (Cham.) Miers & & Trepadeira & & $X$ & \\
\hline Tabebuia aurea (Silva Manso) Benth. \& Hook. f. ex S. Moore & Caraibeira & Árvore & & $\mathrm{X}$ & \\
\hline Tabebuia heterophylla (DC.) Britton * & Ipê-rosa & Árvore & & & $\mathrm{X}$ \\
\hline Tabebuia roseoalba (Ridl.) Sandwith & Ipê-branco & Árvore & & & $\mathrm{X}$ \\
\hline Tanaecium affine (A.H. Gentry) L.G.Lohmann* & - & Trepadeira & $\mathrm{X}$ & & \\
\hline Tanaecium neobrasiliense (Baill.) L.G.Lohmann & - & Trepadeira & $\mathrm{X}$ & & \\
\hline Tanaecium selloi (Spreng.) L.G.Lohmann & - & Trepadeira & $\mathrm{X}$ & & \\
\hline Tecoma stans (L.) Juss. ex Kunth* & Ipê-mirim & Árvore & & $\mathrm{X}$ & $\mathrm{X}$ \\
\hline Tynanthus elegans Miers & Cipó-cravo & Trepadeira & & $\mathrm{X}$ & \\
\hline Xylophragma platyphyllum (DC.) L.G.Lohmann & Cipó-una & Trepadeira & $X$ & & \\
\hline Zeyheria montana Mart. & Bolsa-de-pastor & Arbusto & & $X$ & \\
\hline Zeyheria tuberculosa (Vell.) Bureau & Ipê-branco & Árvore & $\mathrm{X}$ & $\mathrm{X}$ & \\
\hline
\end{tabular}

* Espécies exóticas. 
Tabela 2 - Comparação entre o levantamento de Bignoniaceae no município de Lavras, Minas Gerais e em outras cinco localidades.

Table 2 - Comparison between the survey of Bignoniaceae in Lavras, Minas Gerais and five other locations.

\begin{tabular}{|c|c|c|c|}
\hline Área & Total de espécies & Espécies em comum & Autores \\
\hline $\begin{array}{l}\text { Parque Estadual do Itacolomi (PEI) } \\
\text { Minas Gerais }\end{array}$ & 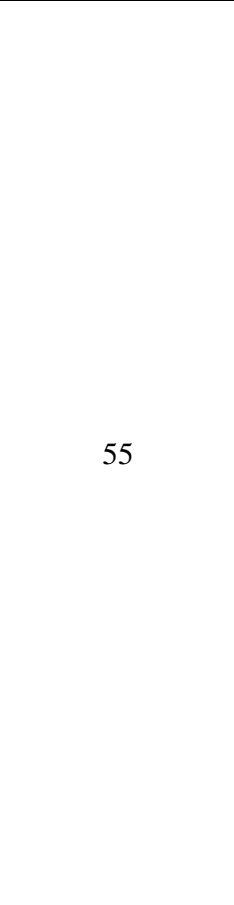 & $\begin{array}{c}\text { Adenocalymma bracteatum } \\
\text { Amphilophium crucigerum } \\
\text { Amphilophium elongatum } \\
\text { Anemopaegma arvense } \\
\text { Anemopaegma chamberlaynii } \\
\text { Cybistax antisyphilitica } \\
\text { Dolichandra unguis-cati } \\
\text { Fridericia florida } \\
\text { Fridericia formosa } \\
\text { Fridericia platyphylla } \\
\text { Fridericia pubescens } \\
\text { Fridericia samydoides } \\
\text { Fridericia speciosa } \\
\text { Fridericia triplinervia } \\
\text { Handroanthus albus } \\
\text { Handroanthus chrysotrichus } \\
\text { Handroanthus vellosoi } \\
\text { Jacaranda macrantha } \\
\text { Jacaranda mimosifolia } \\
\text { Pyrostegia venusta } \\
\text { Stizophyllum perforatum } \\
\text { Tabebuia heterophylla } \\
\text { Zeyheria montana }\end{array}$ & Araújo (2008) \\
\hline
\end{tabular}

Adenocalymma bracteatum

Amphilophium crucigerum

Amphilophium elongatum

Cuspidaria pulchra

Bignonieae no Parque Estadual do Rio Doce (PERD)

Minas Gerais

\section{6}

Região de Catolés, Chapada Diamantina
Bahia

Dolichandra unguis-cati
Fridericia platyphylla
Fridericia pubescens
Scudeller \& Carvalho- Okano (1998)

Fridericia samydoides

Fridericia speciosa

Fridericia triplinervia

Pyrostegia venusta

Stizophyllum perforatum

Cuspidaria pulchra

Cybistax antisyphilitica

Dolichandra unguis-cati

Fridericia platyphylla

Handroanthus ochraceus

Jacaranda caroba

Pyrostegia venusta

Tabebuia aurea

Zeyheria montana

Zeyheria tuberculosa

Silva \& Queiroz (2003)

Continua...

To be continued...

Cerne, Lavras, v. 16, n. 4, p. 517-529, out./dez. 2010 
Tabela 2 - Continua...

Table 2 - Continued...

\begin{tabular}{|c|c|c|c|}
\hline Área & Total de espécies & Espécies em comum & Autores \\
\hline $\begin{array}{l}\text { Parque Nacional da Serra da Canastra (PNSC) } \\
\text { Minas Gerais }\end{array}$ & 15 & $\begin{array}{c}\text { Adenocalymma bracteatum } \\
\text { Amphilophium elongatum } \\
\text { Anemopaegma arvense } \\
\text { Anemopaegma chamberlaynii } \\
\text { Cuspidaria convoluta } \\
\text { Cuspidaria pulchra } \\
\text { Fridericia platyphylla } \\
\text { Handroanthus ochraceus } \\
\text { Jacaranda caroba } \\
\text { Pyrostegia venusta } \\
\text { Zeyheria montana }\end{array}$ & Scudeller (2004) \\
\hline Tecomeae no Parque Nacional do Itatiaia (PNI) & 13 & $\begin{array}{c}\text { Cybistax antisyphilitica } \\
\text { Handroanthus albus } \\
\text { Handroanthus chrysotrichus } \\
\text { Handroanthus heptaphyllus } \\
\text { Handroanthus ochraceus } \\
\text { Handroanthus serratifolius } \\
\text { Handroanthus vellosoi } \\
\text { Jacaranda caroba } \\
\text { Jacaranda subalpina }\end{array}$ & $\begin{array}{l}\text { Pereira \& Mansano } \\
\text { (2008) }\end{array}$ \\
\hline
\end{tabular}

\section{REFERÊNCIAS BIBLIOGRÁFICAS}

AGRA, M. F.; FRANÇA, P. F.; BARBOSA-FILHO, J. M. Synopsis of the plants known as medicinal and poisonous in Northeast of Brazil. Revista Brasileira de Farmacognosia, São Paulo, v. 17, n. 1, p. 114-140, 2007.

AGRA, M. F.; SILVA, K. N.; BASÍLIO, I. J. L. D.; FRANÇA, P. F.; BARBOSA-FILHO, J. M. Survey of medicinal plants used in the region Northeast of Brazil. Revista Brasileira de Farmacognosia, São Paulo, v. 18, n. 3, p. 472-508, 2008.

APPOLINÁRIO, V. Taxocenose de trepadeiras em fragmentos e corredores florestais de Lavras, MG: aspectos estruturais e ecológicos. 2008. 51 p. Tese (Doutorado em Ciências Florestais) - Universidade Federal de Lavras, Lavras, 2008.

ARAÚJO, R. S. Bignoniaceae Juss. do Parque Estadual do Itacolomi, Minas Gerais, Brasil: florística, similaridade e distribuição geográfica. 2008. Dissertação (Mestrado em Botânica) Universidade Federal de Viçosa, Viçosa, 2008.

BIODIVERSITAS. Lista da flora brasileira ameaçada de extinção. Disponível em:'L L florabr/>. Acesso em: 23 ago. 2009.
BUREAU, E.; SCHUMANN, K. Bignoniaceae. Flora Brasiliensis, v. 8, n. 2, p. 2-298, 1897.

CARVALHO, D. A. Flora fanerogâmica de campos rupestres da Serra da Bocaina, Minas Gerais: caracterização e lista de espécies. Ciência e Prática, Lavras, v. 16, n. 1, p. 97-122, 1992.

CARVALHO, D. A.; MARTINS, F. R. A flora arbóreo-arbustiva dos cerrados do sudoeste de Minas Gerais. Cerne, Lavras, v. 15, n. 2, p. 142-154, 2009.

CHENNA, P. H.; DOCTOROVICH, V.; BAGGIO, R. F.; GARLAND, M. T.; BURTON, G. Preparation and Citotoxicity toward Cancer Cells of Mono (arylimino) Derivatives of aLapachone. Journal Medicinal Chemistry, v. 44, n. 15, p. 2486-2489, 2001.

DALANESI, P. E.; OLIVEIRA FILHO, A. T.; FONTES, M. A. L. Flora e estrutura do componente arbóreo da floresta do Parque Ecológico Quedas do Rio Bonito, Lavras, MG, e correlações entre a distribuição das espécies e variáveis ambientais. Acta Botanica Brasilica, Porto Alegre, v. 18, n. 4, p. 737-757, 2004.

Cerne, Lavras, v. 16, n. 4, p. 517-529, out./dez. 2010 
DEPARTAMENTO NACIONAL DE METEOROLOGIA. Normas climatológicas: 1961-1990. Brasília: Ministério da Agricultura, 1992.

ESPÍRITO-SANTO, F. D. B.; OLIVEIRA FILHO, A. T.; MACHADO, E. L. M.; SOUZA, J. S.; FONTES, M. A. L.; MARQUES, J. J. G. S. M. Variáveis ambientais e a distribuição de espécies arbóreas em um remanescente de floresta estacional semidecídua montana no campus da Universidade Federal de Lavras, MG. Acta Botanica Brasilica, São Paulo, v. 16, n. 3, p. 331-356, 2002.

GAVILANES, M. L.; BRANDÃO, M. Flórula da reserva biológica municipal do Poço Bonito, Lavras, MG: I., formação cerrado. Daphne, v. 1, p. 24-31, 1991a.

GAVILANES, M. L.; BRANDÃO, M. Flórula da reserva biológica municipal do Poço Bonito, Lavras, MG: II., formação cerrado. Daphne, v. 2, p. 7-18, 1991 b.

GAVILANES, M. L.; BRANDÃO, M.; OLIVEIRA FILHO, A. T.; ALMEIDA, R. J.; MELLO, J. M.; AVEZUM, F. F. Flórula da reserva biológica municipal do Poço Bonito, Lavras, MG: III., formação florestal. Daphne, v. 2, p. 14-26, 1992.

GENTRY, A. H. Bignoniaceae: part I, tribes crescentieae and tourrentieae. Flora Neotropica, v. 25, n. 1, p. 1-130, 1980.

GENTRY, A. H. Bignoniaceae: part II, tribe Tecomeae. Flora Neotropica, New York, v. 25, p. 370, 1992.

GOBATTO-RODRIGUES, A. A.; STORT, M. N. Biologia floral e reprodução de Pyrostegia venusta (Ker-Gawl) Miers (Bignoniaceae). Revista Brasileira de Botânica, São Paulo, v. 15, n. 1, p. 37-41, 1992.

HIRUMA-LIMA, C. A.; DI STASI, L. C. Scrophulariales medicinais. In: . Plantas medicinais na Amazônia e na

Mata Atlântica. São Paulo: Unesp, 2002. p. 449-452.

INSTITUTO BRASILEIRO DE GEOGRAFIA E ESTATÍSTICA. Cidades. Disponível em: <http:// iwww.ibge.gov.br/cidadesat/topwindow.htm? set. 2009.

LOHMANN, L. G.; PIRANI, J. R. Tecomeae (Bignoniaceae Juss.) da Cadeia do Espinhaço, Minas Gerais e Bahia, Brasil. Acta Botanica Brasilica, Porto Alegre, v. 10, p. 103-138, 1996.
LORENZI, H. Árvores brasileiras: manual de identificação e cultivo de plantas arbóreas do Brasil. 5. ed. Nova Odessa: Instituto Plantarum, 2008. v. 1.

MACHADO, E. L. M.; OLIVEIRA FILHO, A. T.; CARVALHO, W. A. C.; SOUZA, J. S.; BORÉM, R. A. T.; BOTEZELLI, L. Análise comparativa da estrutura e flora do compartimento arbóreoarbustivo de um remanescente florestal na Fazenda Beira Lago, Lavras, MG. Revista Árvore, Viçosa, v. 28, n. 4, p. 493-510, 2004.

NÚÑEZ, V.; OTERO, R.; BARONA, J.; SALDARRIAGA, M.; OSORIO, R. G.; FONNEGRA, R.; JIMÉNEZ, S. L.; DÍAZ, A.; QUINTANA, J. C. Neutralization of the edema-forming, defibrinating and coagulant effects of Bothrops asper venom by extracts of plants used by healers in Colombia. Brazilian Journal Medical Biology Research, v. 37, n. 7, p. 969-977, 2004.

OLIVEIRA FILHO, A. T.; ALMEIDA, R. J.; MELLO, J. M.; GAVILANES, M. L. Estrutura fitossociológica e variáveis ambientais em um trecho da mata ciliar do córrego dos Vilas Boas, Reserva Biológica do Poço Bonito, Lavras, MG. Revista Brasileira de Botânica, São Paulo, v. 17, n. 1, p. 67-85, 1994a.

OLIVEIRA-FILHO, A. T.; FLUMINHAM-FILHO, M. Ecologia da vegetação do Parque Florestal Quedas do Rio Bonito. Cerne, Lavras, v. 5, n. 2, p. 51-64, 1999.

OLIVEIRA-FILHO, A. T.; VILELA, E. A.; GAVILANES, M. L.; CARVALHO, D. A. Comparison of the woody flora and soils of six areas of montane semideciduous forest in southern Minas Gerais. Edinburgh Journal of Botany, Edinburgh, v. 51, n. 3, p. 355-389, 1994b.

PARK, B. S.; KIM, J. R.; LEE, S. E.; KIM, K. S.; TAKEOKA, G. R.; AHN, Y. J.; KIM, J. H. Selective growth-inhibiting effects of compounds identified in Tabebuia impetiginosa inner bark on human intestinal bacteria. Journal Agricultural Food Chemistry, Easton, v. 53, n. 4, p. 1152-1157, 2005.

PEREIRA, P. H.; MANSANO, V. F. Estudos taxonômicos da tribo Tecomeae (BIGNONIACEAE) no Parque Nacional do Itatiaia, Brasil. Rodriguésia, Rio de Janeiro, v. 59, n. 2, p. 265-289, 2008.

PINTO, L. V. A.; DAVIDE, A. C.; BOTELHO, S. A.; OLIVEIRAFILHO, A. T.; MACHADO, E. L. M. Distribuição das espécies arbóreo-arbustivas ao longo do gradiente de umidade do solo de nascentes pontuais da bacia hidrográfica do ribeirão Santa Cruz, Lavras, MG. Cerne, Lavras, v. 11, n. 3, p. 294-305, 2005.

Cerne, Lavras, v. 16, n. 4, p. 517-529, out./dez. 2010 
PORTILlO, A.; VILA, R.; FREIXA, B.; ADZET, T.; CAÑIGUERAL, S. Antifungal activity of Paraguayan plants used in traditional medicine. Journal of Ethnopharmacology, Amsterdam, v. 76, n. 1, p. 93-98, 2001.

QUEIROZ, R.; SOUZA, A. G.; SANTANA, P.; ANTUNES, F. Z.; FONTES, M. Zoneamento Agroclimático do Estado de Minas Gerais. Lavras: UFLA, 1980.

RODRIGUES, V. E. G.; CARVALHO, D. A. Florística de plantas medicinais de remanescentes de floresta estacional semidecidual na região do Alto Rio Grande, MG. Cerne, Lavras, v. 14, n. 2, p. 93-112, 2008.

RODRIGUES, V. E. G.; CARVALHO, D. A. Levantamento etnobotânico de plantas medicinais no domínio dos cerrados na região do Alto Rio Grande-Minas Gerais. Revista Brasileira de Plantas Medicinais, São Paulo, v. 9, n. 2, p. 17-35, 2007.

SANDWITH, N. Y.; HUNT, D. R. Bignoniaceae. Flora Ilustrada Catarinense, Itajaí, p. 1-172, 1974.

SCUDELLER, V. V. Bignoniaceae Juss. no Parque Nacional da Serra da Canastra, Minas Gerais, Brasil. Iheringia, Série Botânica, Porto Alegre, v. 59, n. 1, p. 59-73, 2004.
SCUDELlER, V. V. A tribo Bignonieae Spreng. (Bignoniaceae) no Parque Estadual do Rio Doce, MG. 1997. 214 f. Dissertação (Mestrado em Botânica) - Universidade Federal de Viçosa, Viçosa, 1997.

SCUDELLER, V. V.; CARVALHO-OKANO, R. M. de. Bignonieae (Bignoniaceae) no Parque Estadual do Rio Doce, Minas Gerais, Brasil. Iheringia Série Botânica, Porto Alegre, v. 51, n. 1, p. 79-133, 1998.

SILVA, M. M. da; QUEIROZ, L. P. de. A família Bignoniaceae na região de Catolés, Chapada Diamantina, Bahia, Brasil. Sitientibus Série Ciências Biológicas, v. 3, n. 1/2, p. 3-21, 2003.

SOUZA, J. S.; ESPÍRITO-SANTO, F. D. B.; FONTES, M. A. L.; OLIVEIRA-FILHO, A. T.; BOTEZELLI, L. Análise das variações florísticas e estruturais da comunidade arbórea de um fragmento de Floresta Semidecídua às margens do rio Capivari, Lavras-MG. Revista Árvore, Lavras, v. 27, n. 2, p. 185-206, 2003.

SOUZA, V. C.; LORENZI, H. Botânica Sistemática: guia ilustrado para identificação das famílias de Fanerógamas nativas e exóticas no Brasil, baseado em APG II. 2. ed. Nova Odessa: Instituto Plantarum, 2008. 574 p. 
